\title{
THE EFFECTS OF VARIOUS AGENTS ON THE SOLUBILITY OF ACTOMYOSIN
}

\author{
THE PHENOMENON OF DUAL PRECIPI- \\ TATION OF ACTOMYOSIN*
}

\author{
MASAHIRO FUJINO AND CHIEKO WAKASA** \\ Department of Physiology, Sapporo Medical College, Sapporo, Japan
}

For understanding the mechanism of superprecipitation (1) as the basis of muscular contraction, it is considered to be very important to clarify the mechanism by which salts, which are supposed to be in close connection with actomyosin (AM)-adenosinetriphosphate(ATP) interaction, produce effects on the solubility of $\mathrm{AM}$ in low $\mathrm{KCl}$ concentration at $p_{\mathrm{H}} 7$.

Sarkar (2) (3) studied in detail the effects of salts on myosin (or AM) in order to understand the fundamental mechanism by which myosin (or AM) is precipitated in the presence of small quantities of salts, - the unique property of myosin (or AM) in respect of salts. Nagai pointed out that, not only regarding this unique property but also in other respects, AM closely corresponded to glycerinated muscles (4) (5) (6).

The experiments recorded in the present paper were initiated in order to investigate precisely the close relationship between extensibility of glycerinated muscles and solubility of AM. For this purpose various agents such as $\mathrm{MgCl}_{2}$, $\mathrm{CaCl}_{2}, \mathrm{Na}$-pyrophosphate (PP), ethylendiamine tetraacetate (EDTA), and salyrgan were examined for their effects on the solubility of $\mathrm{AM}$ in low $\mathrm{KCl}$ concentrations at $p \mathrm{H} 7$.

In the course of the experimentation, an interesting phenomenon showing "dual precipitation" was found in which the mechanism of the interaction between AM and salts might be hidden. Therefore, description will be made mainly on this "phenomenon of dual precipitation."

\section{MATERIALS AND METHODS}

Materials. 1) AM (myosin-B) was extracted from rabbit muscle according to Szent-Györgyi's method (7). The extract was washed three times according to Edsall's method (13), dissolved in $0.5 \mathrm{M} \mathrm{KCl}$ and kept stored in a refrigerator until used.

2) All the agents were prepared to give concentrations of $10^{-1}$ (for salyrgan, $\left.5 \times 10^{-2}\right), 10^{-2}, 10^{-3}$, and $10^{-4} \mathrm{M}$.

Received for publication December 7, 1957.

* The outline of this paper was presented at the 33. annual meeting of the Physiological Society of Japan, Okayama, May 23, 1956.

** 藤野和宏, 若涨智恵子 
3) In order that the reaction may be limited to occur under desired conditions, use was made of distilled water, 0.2 and $0.6 \mathrm{M} \mathrm{KCl}$ solutions.

4) For the preparation of all the stock solutions mentioned above, glassredistilled water was employed. The $p \mathrm{H}$ of each solution was adjusted to 7 by adding $\mathrm{KOH}$ (or $\mathrm{NH}_{4} \mathrm{OH}$ ), $\mathrm{HCl}$ (or $\mathrm{CH}_{3} \mathrm{COOH}$ ) as occasion demands.

Methods. Experiments were performed at constant temperature $\left(18^{\circ}-20^{\circ} \mathrm{C}\right)$ in a water bath.

The grade of solubility of $\mathrm{AM}$ in varying $\mathrm{KCl}$ concentrations $(0.05-0.3 \mathrm{M})$ were examined, using 81 test tubes at a time. In order that the results may be accurate, this procedure was repeated five to seven times for each agent with different AM samples prepared from different rabbits.

The test tubes used were all of the same diameter. The total volume of the reaction mixture in each test tube was $2 \mathrm{cc}$. The reaction was started by adding to each test tube a suitable volume of the stock solution of AM. The final protein concentration was about $0.8 \mathrm{mg} / \mathrm{cc}$.

Determination of the grade of solubility was repeated two times, 20 minutes and about 18-24 hours after the set-out of the reaction. At the first time, the determination was made by observing and recording the turbidity and the quality of the flock, and at the second time, by measuring the height of the column of precipitate after the test tubes were shaken. In each experiment, the solubility of $\mathrm{AM}$ at $0.05 \mathrm{M} \mathrm{KCl}$ in the absence of the agent to be tested was taken as standard for comparison and given the value of 4 , then the solubility in all the test tubes was graded $5,4,3,2,1,0$, according to its intensity, the value of 5 showing the minimum solubility. The accuracy of this method was confirmed by comparing these values with the spectrophotometrically $(\lambda=280 \mathrm{~m} \mu)$ measured values in $0.6 \mathrm{M} \mathrm{KCl}$ of the protein concentration in the supernatants (see fig. 3-c).

RESULTS

The results obtained were presented in figures 1 to 5 , together with the photographs of the reactions from which the measurements of the solubility were made.

(1) $\mathrm{MgCl}_{2}$ : (Fig. 1). Two transverse zones of precipitation, or zones of lowgrade solubility are seen at the left lower part of the figure apart from each other. This indicates that in low $\mathrm{KCl}$ concentrations, the solubility of $\mathrm{AM}$ fails to run parallel with the increase of $\mathrm{MgCl}_{2}$ concentration, but it shows dual decrease in the interim. The authors designated this phenomenon "phenomenon of dual precipitation." The solubility of AM was highest at the right upper part of the figure.

(2) $\mathrm{CaCl}_{2}:$ (Fig. 2). The general tendency was similar to that of figure 1 . The "phenomenon of dual precipitation" was observed in low $\mathrm{KCl}$ concentrations, the solubility of AM being highest at the right upper part of the figure. Only in this case, the solubility of AM was lower than in the case of $\mathrm{MgCl}_{2}$.

(3) Na-pyrophosphate: (Fig. 3). The tendency was the same as in the case of $\mathrm{MgCl}_{2}$ and $\mathrm{CaCl}_{2}$. But, in this case, the grade of solubility of $\mathrm{AM}$ was more comparable to $\mathrm{MgCl}_{2}$ than to $\mathrm{CaCl}_{2}$. 

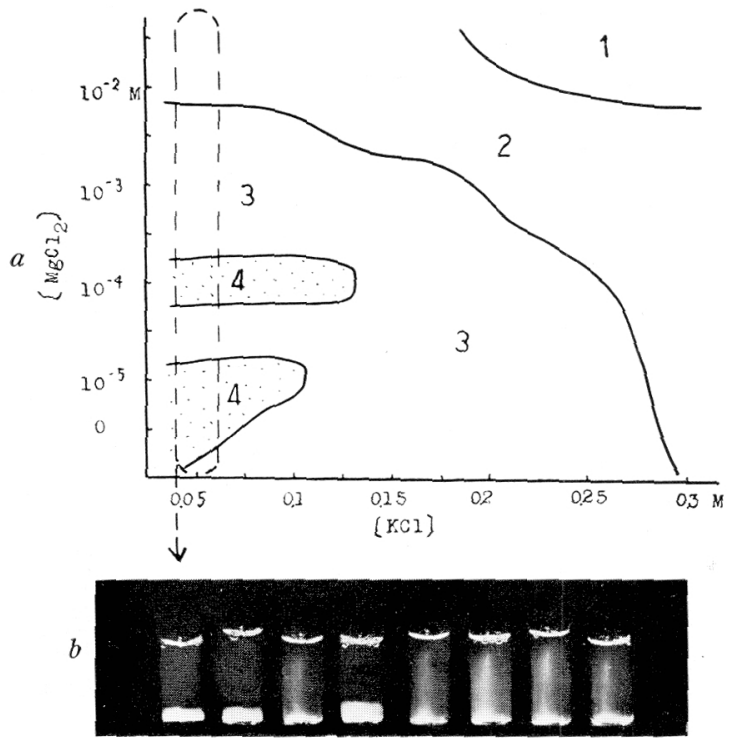

$0 \quad 10^{-5} 5 \times 10^{-5} 10^{-4} 5 \times 10^{-4} 10^{-3} 5 \times 10^{-3} 10^{-2} \mathrm{M}$

$\left[\mathrm{MgCl}_{2}\right]$
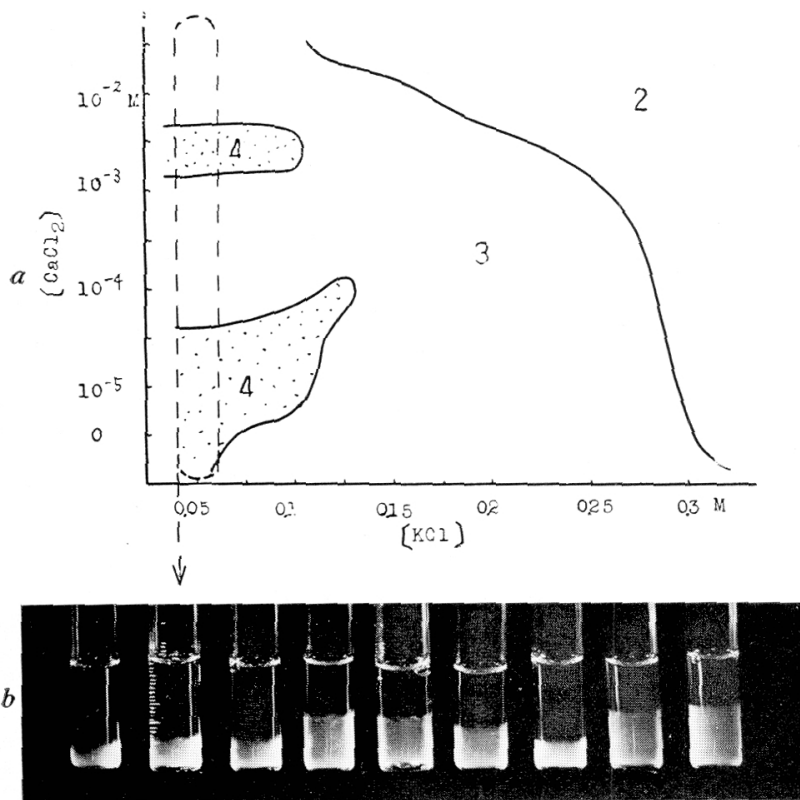

$0 \quad 10^{-5} 5 \times 10^{-5} 10^{-4} \quad 5 \times 10^{-4} 10^{-3} \quad 5 \times 10^{-3} 10^{-2} \quad 5 \times 10^{-2} \mathrm{M}$

$\left[\mathrm{CaCl}_{2}\right]$
FIG. 1. The solubility of AMsolution at varying concentrations of $\mathrm{MgCl}_{2}$ and $\mathrm{KCl}$.

$a$ : Precipitation grade of $\mathrm{AM}$ solution in the presence of $\mathrm{MgCl}_{2}$ and $\mathrm{KCl}$.

The numbers indicate the grades of precipitation.

$p \mathrm{H}: 7.0$.

Temperature : $18^{\circ}-20^{\circ} \mathrm{C}$.

Protein concentration: $0.85 \mathrm{mg} / \mathrm{cc}$.

$b$ : Photograph of the part enclosed by the broken line in ( $a$ ) (20 hours after reaction).

The precipitate-like white zones at the bottom of the third tube from the left hand and of the four tubes on the right hand show only diffused light.

FIG. 2. The solubility of AMsolution at varying concentrations of $\mathrm{CaCl}_{2}$ and $\mathrm{KCl}$.

$a$ : Precipitation grade of AMsolution in the presence of $\mathrm{CaCl}_{2}$ and $\mathrm{KCl}$. (Under the same conditions as in fig. 1.)

$b$ : Photograph of the part enclosed by the broken line in $(a)$ ( 20 hours after reaction). 


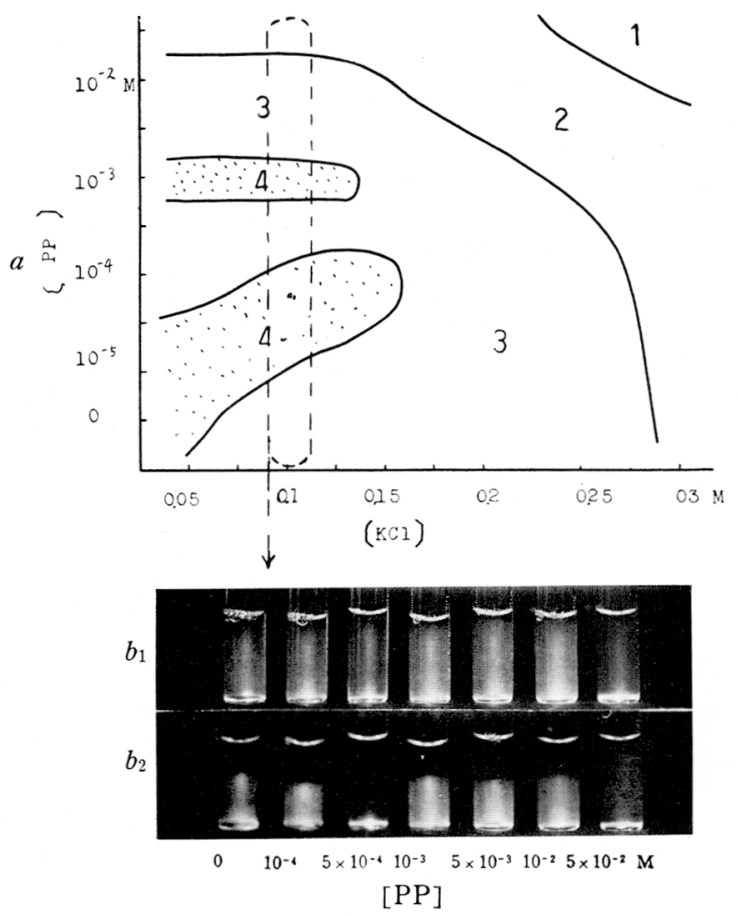

FIG. 3. The solubility of AM-solution at varying concentrations of $\mathrm{PP}$ and $\mathrm{KCl}$.

$a$ : Precipitation grade of AM-solution in the presence of PP and $\mathrm{KCl}$. (Under the same conditions as in fig. 1.)

$b$ : Photographs of the part enclosed by the broken line in $(a)$. ( $b_{1}: 20$ minutes after reaction, $b_{2}: 18$ hours after reaction.)

The precipitate-like white zones at the bottom of the tube at the right hand and of the third tube from the left hand show only diffused light.

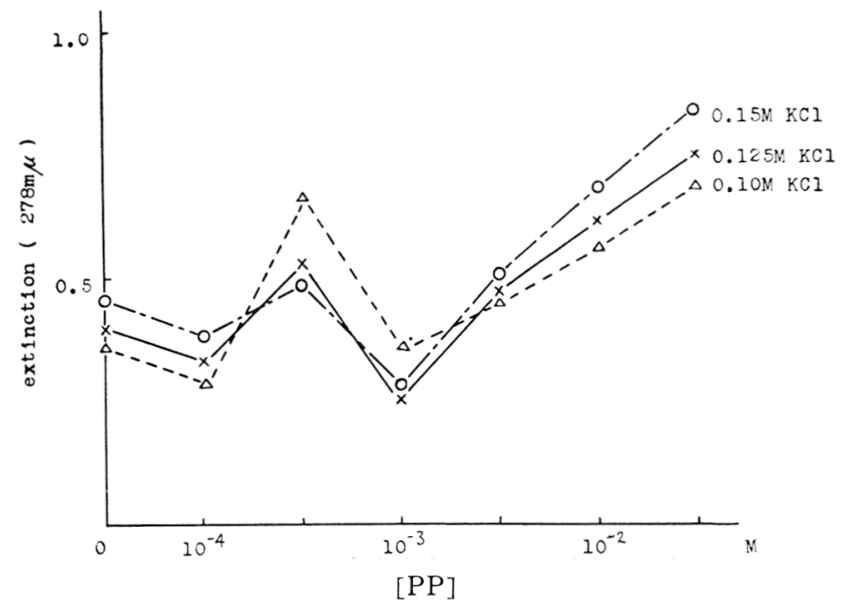

FIG. 3-c. Quantitative expression corresponding to the third, fourth, and fifth columns from the left to the right in fig. 3- $a$.

$p \mathrm{H}:$ 7.0. Protein concentration: $1.5 \mathrm{mg} / \mathrm{cc}$.

The other conditions are the same as in fig. 3-a. 
(4) EDTA: (Fig. 4). In this case the "phenomenon of dual precipitation" was not apparent and only one zone of precipitation was noticed, though, as in the foregoing cases, the solubility of AM was highest at the right upper part of the figure and the zone of low grade solubility was observed towards low $\mathrm{KCl}$ concentration (left lower part). However, from the shape of the zone, one may rightly presume that the "phenomenon of dual precipitation" has been masked under this experimental condition, as the two zones of precipitation, which may be otherwise apparent, have become confused at each other's ends and shifted leftwards in the figure.
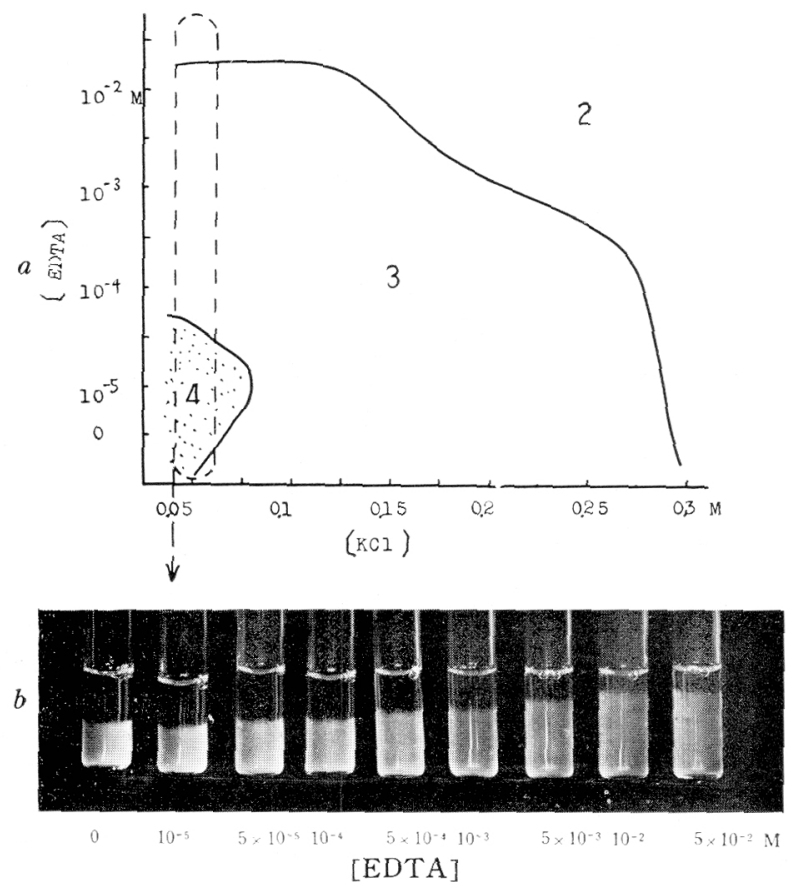

FIG. 4. The solubility of AM-solution at varying concentrations of EDTA and $\mathrm{KCl}$.

$a$ : Precipitation grade of AM-solution in the presence of EDTA and $\mathrm{KCl}$. (Under the same conditions as in fig. 1.)

$b$ : Photograph of the part enclosed by the broken line in $(a)$ (18 hours after reaction).

(5) Salyrgan: (Fig. 5). A partial difference was noticed, though the general tendency was the same as in the foregoing cases. Towards high concentrations of salyrgan, a third supplemental zone of precipitation appeared in addition to the two zones of precipitation corresponding to those in the foregoing cases. The right end of this third zone was in connection with the right end of the upper one of the ordinary two zones. The precipitates of this third zone appeared compact, apparently differing from the aspect of the precipitate of the two other 
zones and from those of the ordinary two zones in case of the other agents described above. In case of salyrgan, the solubility of AM was generally low at the left lower part of the figure, while it was very high at the right upper part of the figure.

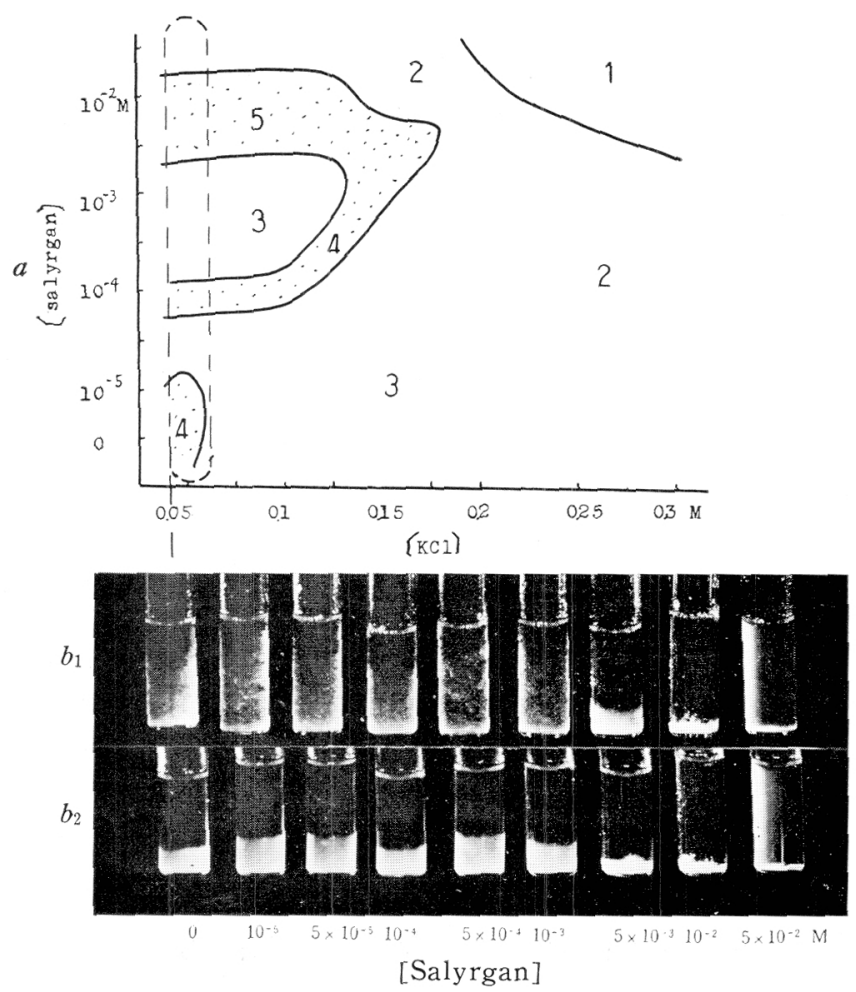

FIG. 5. The solubility of AM-solution at varying concentrations of salyrgan and $\mathrm{KCl}$.

$a$ : Precipitation grade of AM-solution in the presence of salyrgan and $\mathrm{KCl}$. (Under the same conditions as in fig. 1.)

$b_{1}, b_{2}$ : Photographs of the part enclosed by the broken line in $(a)$. ( $b_{1}: 30$ minutes after reaction, $b_{2}: 19$ hours after reaction.)

The precipitate-like white zone at the bottom of the tube at the right hand shows only light diffusion.

\section{DISCUSSION}

As was noticed in the present experiments, the "phenomenon of dual precipitation" appeared in the presence of all the salts or agents employed. This phenomenon may be one of the peculiar characteristics of AM. Since this phenomenon occurs under the physiological conditions of low $\mathrm{KCl}$ concentration at $p_{\mathrm{H}} 7$, this seems to be worthy of attention. Clarifying the mechanism of this phenomenon seems important, because it may lead to understanding the mecha- 
nism of muscular contraction in which the peculiar behavior of AM is involved. Moreover, the "phenomenon of dual precipitation" in the case of PP is worthy of special notice, because the molecular structure of this agent resembles that of ATP. This fact strongly suggests the possibility of the "phenomenon of dual precipitation" being also produced by ATP. It suggests also the possible existence of a close relationship between this phenomenon and superprecipitation.*

Sarkar (2) reported already the shifting of the isoelectric point (IP) of myosin (or $\mathrm{AM}$ ) in the following cases: 1) when the concentrations of $\mathrm{KCl}$ and $\mathrm{MgCl}_{2}$ increase in the absence of other salts, 2) when the concentrations of $\mathrm{KCl}$ increase at a constant concentration of $\mathrm{MgCl}_{2}$ (fig. 6). He observed that the maximum point of the IP-shift due to $\mathrm{KCl}$ was at $p \mathrm{H} 7$, and that to $\mathrm{MgCl}_{2} p_{\mathrm{H}} 8$. Now, if the correlation among the values of $p \mathrm{H},[\mathrm{KCl}]$ and $\left[\mathrm{MgCl}_{2}\right]$ obtained in his experiments is expressed in a three-dimensional pattern, a curved surface as shown in figure 7 can be obtained indicating isoelectric precipitation. Let us then cut this curved surface with the plane of $p_{\mathrm{H}} 7$, and we obtain two

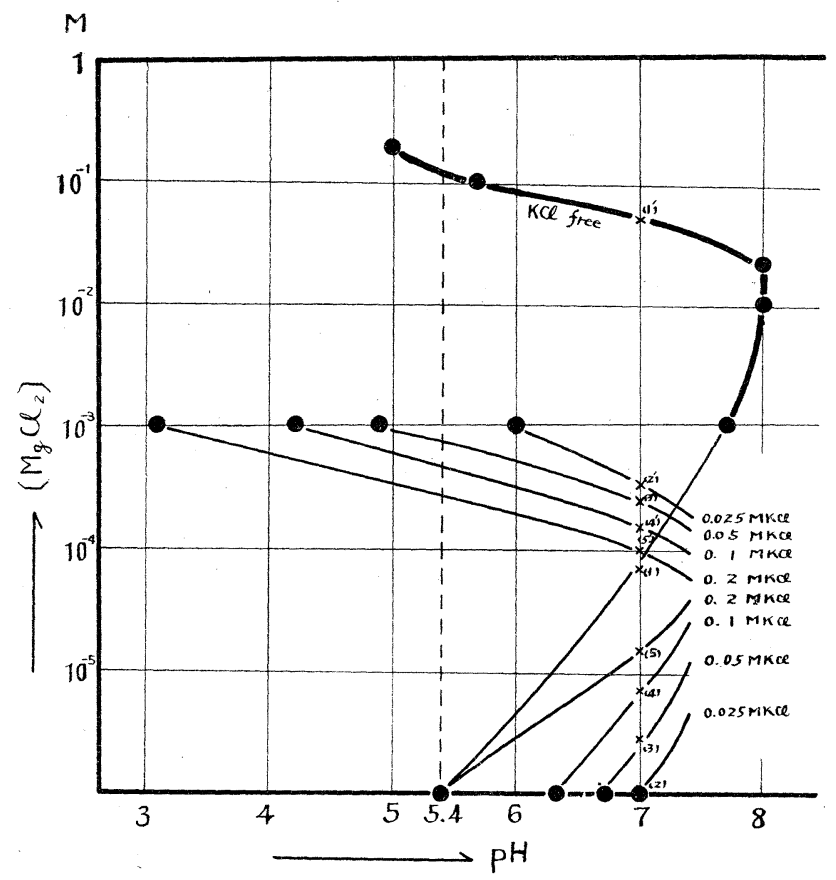

FIG. 6. Graphs obtained by projecting Sarkar's results (2) to the $p \mathrm{H} \cdot\left[\mathrm{MgCl}_{2}\right]$ plane, in order to obtain the basis of the threedimensional expression of figure 7.

The thin lines are imaginary, the thick one is actual line. The large black points represent the actual values measured, and ' $x$ 's represent the crossing points between the $p \mathrm{H} 7$ line and the above mentioned imaginary and measured lines.

* In the successive experiments, the experimental confirmations for these problems have been obtained (14) (17), 


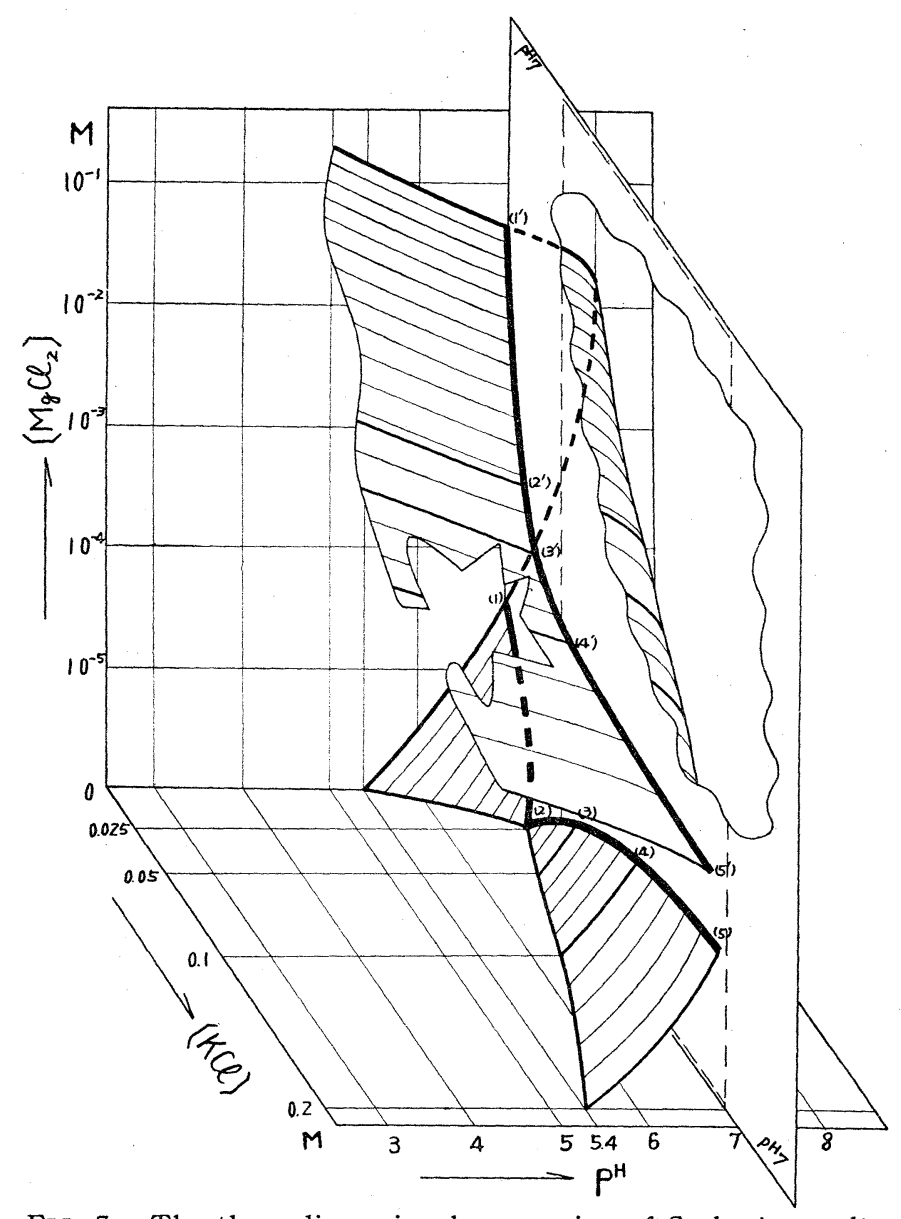

FIG. 7. The three-dimensional expression of Sarkar's results (2) (cf. fig. 6).

The part enclosed by the thin broken lines in the plane of $p \mathrm{H} 7$ corresponds to figure 1- $a$.

curved lines formed on the plane as shown in figures 7 and 8 . Perusal of these two curved lines, formed at $p_{\mathrm{H}} 7$, reveals that they reflect well the data obtained by the present authors in regard of $\mathrm{MgCl}_{2}$ (fig. 8 and fig. 1-a).

On the basis of the above fact, the "phenomenon of dual precipitation" of AM can be said to appear when the maximum point of the IP-shift due to the salts or agents to be tested is over $p_{\mathrm{H}} 7$.

Now, since all the salts tested in the present experiments have caused to appear the "phenomenon of dual precipitation" in regard of AM, these salts may be said to have an ability to shift the IP of AM over pir 7 at their certain concentrations (except for EDTA of which the shift appeared weak in the present experiments). The validity of this presumption was confirmed by the fact that $\mathrm{CaCl}_{2}$ definitely shifted the IP of AM to the alkaline side (8). 


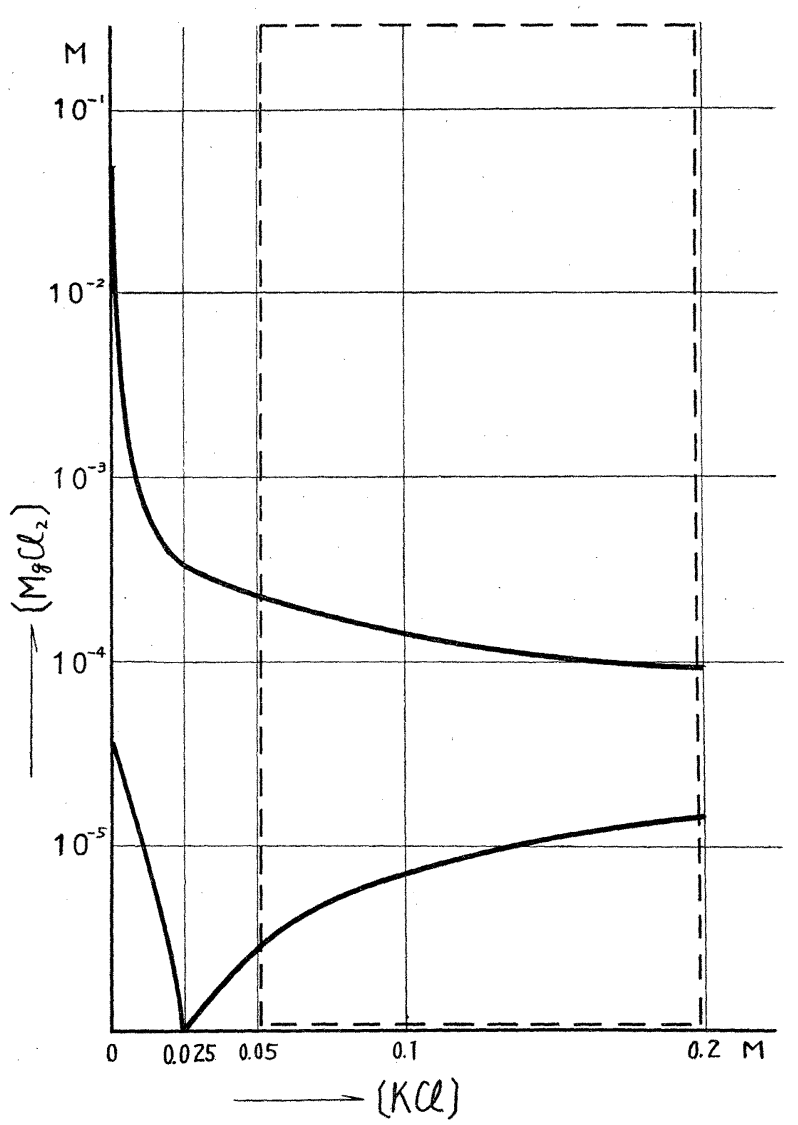

FIG. 8. Front view of the plane of $p \mathrm{H} 7$ in figure 7 .

The part enclosed by the broken lines in the plane of $p \mathrm{H} 7$ corresponds to figure 1-a, as stated in figure 7 .

The above mentioned facts have led the present authors to the conclusion that the key-point to clarify the mechanism of the "phenomenon of dual precipitation" may be in clarifying the mechanism by which the IP of AM is strongly shifted under the influence of the agents tested (this shift-effect, though weak, under the influence of salts seen for other proteins (e.g. casein (9)). If it be so, the following two problems remain to be solved. By what mechanism does the shift-effect of IP of AM occur under the influence of salts, and why is this effect strong in the case of AM? That is to say, the strong shift-effect of salts on AM is particularly worthy of notice as one of the peculiar characteristics on the part of AM as a contractile protein.

The above discussions are all based on the fact that such precipitation is isoelectric in nature. Recently, however, some investigators appear to have doubt as to whether the above mentioned precipitation of AM under the influence of a salt is isoelectric in nature. Namely, A. G. Szent-Györgyi (10) has suggested 
that such precipitation can occur as a result of some factor other than a shift in IP, e.g., intramolecular or intermolecular, simultaneous discharge of the positive and negative groups and their subsequent aggregation. Erdös (11) has stated that such precipitation is not a function of the net charge of AM-molecules. Accordingly, one must first take into consideration these views in interpreting the mechanism of the "phenomenon of dual precipitation." *

\section{SUMMARY}

The study was made of the effects of various agents $\left(\mathrm{MgCl}_{2}, \mathrm{CaCl}_{2}, \mathrm{Na}\right.$ pyrophosphate, ethylendiamine tetraacetate (EDTA), and salyrgan) on the solubility of actomyosin under the influence of low concentrations of $\mathrm{KCl}$, at pн 7 .

The results obtained were as follows:

(1) In the presence of $\mathrm{KCl}$ of physiological concentration at $p \mathrm{H} 7$, each agent examined had dual precipitating action on actomyosin, as the concentration of the agent increases ("phenomenon of dual precipitation").

(2) In the case of EDTA, the "phenomenon of dual precipitation" was slightly modified, and in the case of salyrgan, a third supplemental zone of precipitate appeared at a high concentration of salyrgan.

(3) The authors have pointed out that the "phenomenon of dual precipitation" is worthy of attention as one of the peculiar characteristics of actomyosin and as one important key-point to clarify the mechanism of superprecipitation or muscular contraction.

\section{ACKNOWLEDGEMENT}

The authors are indebted to Prof. T. Nagai, Prof. E. Miyazaki, and Assist. Prof. Y. Terayama, Department of Physiology, Sapporo Medical College, for their valuable criticism in the course of the work. The authors wish to express their thanks to Prof. Y. Takahashi, Research Institute for Tuberculosis, Hokkaido University, for his valuable advice throughout the course of the translation of the present paper from the Japanese into the English.

\section{REFERENCES}

1. Szent-Györgyi, A. Chemistry of Muscular Contraction, 2. Ed., p. 75. New York: Acad. Press, 1951.

2. SARKAR, N. K. Enzymologia $14: 237,1950$.

3. SARKAR, N. K. Enzymologia $15: 1,1951$.

4. NAGAI, T. ET AL. Sapporo Med. J. $5: 154,1954$.

* Recently, Spicer et al. (12) have reported their results concerning the two zones of precipitation in myosin which appeared at a certain ionic strength (or $\mathrm{KCl}$ concentration) and $p H$. Since this fact is important in respect to the above discussions and to clarifying the mechanism of the precipitation described above, the authors have studied in detail the phenomenon reported by Spicer et al. And it has been clarified (15) (16) that the mechanism of the "phenomenon of dual precipitation" be different from that of the two zones of precipitation described by Spicer et al. 
5. Nagai, T. ET AL. Jap. J. Physiol. 5 : 301, 1955.

6. NAGAI, T. Physical Chemistry of Muscular Contraction, 1. Ed., p. 223. Tokyo: Igakushoin, 1956.

7. Szent-Györgyi, A. Chemistry of Muscular Contraction. New York: Acad. Press, 1947.

8. SNellman, O. AND ERDÖs, T. Nature 161: 526, 1948.

9. Szent-Györgyi, A. Chemistry of Muscular Contraction, 2. Ed., p. 43. New York: Acad. Press, 1951.

10. Szent-Györgyi, A. G. Advances in Enzymology $16: 313,1955$.

11. Erdös, T. Acta Physiol. (Budapest) 7: 1, 1955 cit. in Berichte 178: 314, 1955.

12. Spicer, S. S. And Weise, V. K. Arch. Biochem. Biophys. 59: 345, 1955.

13. Edsall, J. T. J. Biol. Chem. 133: 397, 1940.

14. WAKASA, C. Sapporo Med. J. 10: 1, 1956.

15. FuJINO, M. AND FuKui, S. unpublished.

16. FUkUI, S. Sapporo Med. J. 12: 8, 1957.

17. FuJINO, M. AND WAKASA, C. unpublished. 